\author{
H.A. Нарбуm* \\ *Институт водных и экологических проблем ДВО РАН \\ Тихоокеанский государственный университет \\ Хабаровск, Россия, nina-narbut@rambler.ru
}

\title{
ECOLOGICAL CARCASS AS A MODELFOR URBAN AREA ORGANIZATION
}

\author{
N.A. Narbut* \\ *Institute for Aquatic and Ecological Problems of FEB Russian Academy of Sciences \\ Pacific National University \\ Khabarovsk, Russia,nina-narbut@rambler.ru
}

\begin{abstract}
The existingzoning ofurban areain city-planningdocumentsdoes not comply with the objectives ofsustainable development. The conceptof the ecological carcassurban area is proposed to serve as amodel for urban area organization.
\end{abstract}

Keywords: sustainable development, zoning ofurban area, ecological carcass.

Введение. Организация территории - система управления природопользованием путем распределения земель между землепользователями, исходя из совокупности интересов общества. В каждом конкретном случае эта цель может быть достигнута разными путями и средствами с использованием различных критериев [7]. Следует отметить, что организация территории представляет собой довольно сложную задачу, так как при ее решении должны быть учтены экономические, экологические, социальные интересы, которые часто не совпадают как в функциональном, так и в пространственном отношении. При этом необходимо учитывать региональные особенности территории, включающие геополитическое положение, индивидуальность, которая определяется специализацией, культурно-историческими и природными составляющими, а так же этап освоения (старого, нового, пионерного) и стадию урбанизации $[8,9]$.

Организация городской территории - целенаправленной закрепление земель определенного функционального назначения, составляющих единый планировочный комплекс города, которое должно обеспечить оптимальные условия жизни, производственной деятельности населения и эффективность использования городской территории. Ее основная задача - определение назначений территории, путем установления функциональных зон для конкретного использования земель, стремление к созданию оптимальной модели, в которой хозяйственные и экологостабилизирующие функции земель были бы выдержаны по нормативам.

Градостроительная политика городов определяется генеральными планами. В Хабаровске генеральный план, являясь стратегическим документом, рассчитан осуществлять градостроительное и земельное регулирование до 2025 г., скорректирован с системой правового зонирования. Эта система разработана с целью повышения отдачи городской территории с финансовых позиций в сочетании с мерами, способствующими росту привлекательности городской территории для проживания и деятельности населения, учета всех природоохранных законов, требований и ограничений. Правовое зонирование (правила землепользования и застройки) - принципиально новый документ, который создает условия регулирования территориального развития при переходе к рыночным отношениям [10]

Несмотря на то, что правила землепользования и застройки являются новым документом, в нем сохраняется традиционное зонирование городской территории. Для Хабаровска, например, выделены следующие зоны: центральные/коммерческие, жилые, промышленные, коммунальные, специальные, рекреационные территории и сельскохозяйственного назначения. В свою очередь рекреационные территории включают ООПТ, городские парки, бульвары и набережные, рекреационно-ландшафтные территории и коллективные сады. Основные их функции в градостроительных документах рассматриваются как природоохранные и рекреационные. Однако принятое зонирование не вполне удовлетворяет требованиям устойчивого развития территорий, где, в первую очередь, приобретают значение средоформирующие и средостабилизирующие функции земель. Земли, обладающие этими функциями, формируют микроклимат, способствуют сохранению генофонда биоразнообразия, наиболее ценных экосистем, наземной и почвенной фауны. Они участвуют в регуляции ветрового режима, стабилизации качества воды и нормального гидрологического режима, выполняют эрозионно-стабилизирующую функцию, эталонную, учебно-воспитательную, обеспечивают комфортность проживания и ряд других.

Постановка проблемы. С градостроительными документами тесно увязаны целевые экологические программы, которые являются важным документом, определяющим деятельность администрации города на достижение необходимых параметров качества городской среды. Они разрабатываются на более короткий срок, как правило, унифицированы для всех городов и ориентированы на охрану атмосферного воздуха и водных объектов, развитие природного комплекса, управление движением отходов, экологическое просвещение населения. То есть в тактических документах, которыми являются экологические программы, так же как и в стратегических, вопросы устойчивого развития городской территории не отражены. Поэтому суще- 
ствует необходимость рассмотрения новых подходов к решению этих вопросов. Одним из них может быть использование экологического каркаса как модели пространственной организации городской территории.

Объекты и методы исследования. В качестве объекта исследования выбран город Хабаровск. Это крупный административный, промышленный и культурный центр с населением 580,6 тыс. человек, насчитывающий 487 крупных и средних предприятий, в том числе по производству нефтепродуктов, пищевых продуктов, машин и оборудования, электроэнергии, газа и воды. С позиции экологического планирования он выделяется градостроительной спецификой, определяемой характером расчленения рельефа и сохранением элементов естественных природных компонентов с уникальными объектами растительного и животного мира. В программах развития он определен как перспективная территория для подъема экономики в пределах Дальнего Востока в целом. Хабаровск - приграничный город, что накладывает особые обязательства на проводимую здесь экологическую политику, поскольку через политику приграничных территорий реализуется стратегия национальной безопасности, исходя из складывающейся ситуации в сопредельных территориях [5]. В настоящее время предложено несколько подходов к организации территории. Целесообразным представляется рассмотрения концепции экологического каркаса территории. Подход включает экологофункциональное зонирование, применение картографического и сравнительно-географического методов.

Результаты исследования и их обсуждение. Улучшение экологического состояния города Хабаровска, начиная с 2001 г., осуществляется выполнением мероприятий, предусмотренных в целевых экологических программах. На сегодняшний день их выполнено две (на период 2001-2005 гг. и 2006-2010 гг.), в настоящее время выполняется третья [2]. Первая программа была направлена на решение первоочередных острых экологических проблем, вызванных затянувшимся экономическим кризисом, который характеризовался глубоким спадом производства, сокращением, а зачастую и полным отсутствием финансовых отчислений субъектами хозяйственной деятельности на реализацию природоохранных мероприятий. Программа определила пять основных направлений экологической деятельности администрации города. Это - защита воздушного бассейна города, охрана и рациональное использование водных ресурсов, защита окружающей человека среды от отходов производства и потребления, воспроизводство зеленых насаждений, улучшение экологического образования и просвещения населения города. Была поставлена цель: на 10-15\% сократить выбросы и сбросы загрязняющих веществ в атмосферу и водные объекты города; уменьшить до $50 \%$ количество выводимых в природную среду отходов всех видов за счет вовлечения их в хозяйственный оборот посредством вторичной переработки. Количество и качество зеленых насажденийприблизить к экологическим стандартам; создать условия для формирования безопасных и благоприятных условий жизни людей на территории города. Из-за отсутствия необходимого финансирования не все намеченные мероприятия были выполнены. Тем не менее, за 2001-2005 гг. удалось разработать и реализовать ряд природоохранных мероприятий, которые улучшили экологическое состояние города и позволили решить многие социальные вопросы населения, но проблемы оставались.

Вторая программа в отличие от первой формировалась в других условиях. Уже был сделан шаг в снижение неблагоприятного воздействия различных сфер деятельности на окружающую человека среду. Стояла задача не только удержать, но и значительно улучшить достигнутые ранее показатели. Однако основные направления деятельности администрации в области улучшения качества окружающей среды были сохранены.

Анализ выполнения природоохранных мероприятий, предусмотренных в обеих программах, показал, что экологическое состояние Хабаровска существенно улучшилось [1]. Например:

- появилась устойчивая динамика снижения выбросов загрязняющих веществ в атмосферный воздух, что позволилоисключить Хабаровск из списка городов с высоким уровнем загрязнения воздушной среды, в котором он находился долгие годы;

• произошло улучшение качестваводы в Амурской протоке и некоторых малых реках в черте горо-

да;

- существенно сократились потери воды при ее транспортировке, оборотное и повторное водоснабжение достигло 796,48 млн. м³/г.;

- приостановлено нежелательное развитие основного русла Амура путем строительства каменных полузапруд в истоках проток Пемзенская и Бешеная. Это позволило существенно увеличить расход воды в Амуре непосредственно в пределах города;

• полностью решен не только для города, но и края вопрос утилизации токсичных отходов первого класса - ртутьсодержащих ламп и приборов;

• увеличилось число предприятий по переработке отходов производства и потребления, объем переработки пластиковых отходов стал больше;

- начала решаться проблема захоронения ТБО;

- разработана информационная компьютерная база данных «Зеленые насаждения города Хабаровска» для обобщения и аналитической обработки материалов инвентаризации городских зеленых насаждений и растительности пригородной зоны [4];

• город на Всероссийских конкурсах по благоустройству и озеленению в2002, 2004-2008 гг. занимал призовые места. 
Положительный опыт выполнения мероприятий, предусмотренных городскими программами Хабаровска, способствовал улучшению природной среды города.Но, несмотря на достигнутые успехи, экологическая обстановка на территории Хабаровска по многим показателям не удовлетворяла современным требованиям устойчивого развития урбосистем, оставалось ряд проблем, требующих своего решения.Это определило необходимость разработки новой программы по улучшению экологического состояния города, но прежде необходимо было выявить причины, не позволившие более эффективно выполнить мероприятия, включенные в предыдущую программу. Анализ показал, что их несколько:

- во-первых, недостаточное финансирование;

- во-вторых, существующие подходы оценки состояния городской среды не смогли учесть все имеющиеся проблемы, включая региональные особенности территории города;

- в-третьих, оценка эффективности некоторых планируемых мероприятий сводилась к объему его финансирования. Поскольку деятельность предприятия не всегда была ориентирована на достижение конкретных результатов в области улучшения состояния природной среды, проведенные технические и технологические мероприятия не дали ощутимого эффекта;

• в-четвертых, ожидаемый экологический эффект, зачастую, носил декларативный характер: сокращение выбросов загрязняющих веществ в атмосферу, снижение аварийных выбросов, рациональное использование водных ресурсов, сокращение количества неутилизированных отходов, создание нормативноправовой системы управления ООПТ и т.д.

Это обусловило необходимость внесения некоторые изменения в содержание новой Долгосрочной целевой программы по улучшению экологического состояния города Хабаровска, рассчитанной на период 2011-2015 гг. [2].

В настоящее время во многих странах мира целевые экологические программы играют большую роль в улучшении экологического состояния городов. Анализируя положительный опыт выполнения таких программ, А.С. Курбатова и Е.Н. Корнева [11] сделали обобщение о возможных направлениях развития экологических процессов в урбанизированных территориях в XXI в. Авторы считают, что их три.

Первое осуществляется без перепланировки и глобальной реконструкции города, оно включает экологизацию энергетики, промышленности и транспорта. Основные мероприятия при этом направлены на: уменьшение шума и загрязнения воздуха; увеличение площади зеленых насаждений; экономию тепла и электричества, использование солнечных батарей и биогазовых установок; внедрение новых, малоотходных и экологически чистых технологий, очистку сточных вод, переработку бытовых и промышленных отходов.

Второе направление экологизации - реконструкция структуры старых городов и строительство новых с учетом современных экологических нормативов и стандартов, сохраняя при этом природные ландшафты. Это преимущественно города с населением от 25 до 100 тыс. жителей. Их можно разделить на три типа: новые города-саттелиты, расположенные близко к мегаполисам; свободно существующие новые города, далеко отстоящие от мегаполисов; новые внутримегаполисные города, создаваемые в существующих мегаполисах на месте сносимых кварталов (трущобы, ликвидируемые промышленные или транспортные узлы, базы и т.д.).

Третье направление - это реализация комплексной национальной и глобальной социальноэкономической политики поэтапного ослабления развития гиперурбанизации и ее пагубного воздействия на биосферу. Мероприятиями этого направления уже частично занимаются и в будущем более активно должны заниматься такие международные организации, как ООН, специальные международные комиссии и комитеты, осуществляющие разработку и реализацию многих международных программ. К их числу относится регулирование процессов роста населения и его миграций; устойчивое, эколого-экономически сбалансированное развитие наций и нашей цивилизации в целом; предотвращение негативных глобальных климатических изменений, в развитии которых большую роль играют мегаполисы планеты [11].

Необходимо отметить, что такое направление решения экологических проблемхарактерно для регионов старого освоения, которые находятся на четвертой и частично пятой стадии урбанизации. Здесь происходит развитие городских агломераций, деконцентрация населения, отсутствие свободного пространства.Территория Дальнего Востока как регион нового освоения имеет ряд особенностей, отличных от староосвоенных регионов [8]. Она относится ко второй и началу третьей фазы урбанизации. Вторая фаза характеризуется быстрым ростом городов (городское население растет быстрее сельского), возникновением и развитием «точечных» форм высокой концентрации населения под влиянием усиливающихся различий в выгодах транспортного положения. [9]. При этом взаимодействия урбанизированной и природной среды приобретают уже не только локальные, но и региональные формы. Идут более глубокие изменения в природной среде, антропогенные нагрузки распространяются на обширные территории. Тем не менее, сохраняются значительные территории для установления экологического баланса, сохранения почвенного плодородия. Существенные преобразования на этой стадии урбанизации происходят и в пределах городской черты конкретного города. Следует отметить, что особенностью Дальневосточных городов является индустриальная доминанта в ущерб социальным и экологическим параметрам, пониженная степень комфортности, а не редко и экстремальность в условиях проживания, низкое качество городской среды при наличии значительного свободного пространства. 
Наличие значительного количества межгородского и городского свободного пространства на территории Дальнего Востока, в отличие от регионов старого освоения, позволяет решать экологические проблемы несколько иным способом, способствующим устойчивому развитию городской территории.

Для эффективного использования городских земель, которое является одним из условий устойчивого развития территории, необходимо: во-первых, выявить основные функции земель, придав им социальноэкономический статус (средоформирующие, средостабилизирующие, ландшафтно-терапевтические, обеспечивающие комфортность проживания, рекреационные, эталонные, учебно-воспитательные и др.); вовторых, отслеживать их выполнение, внося необходимую корректировку. Все земли, обладающие экологическими функциями, должны быть выделены в особую группу - земли экологического назначения. Эти земли - основное звено в системе оптимальной организации территории, представляющей модель, которая должна быть ориентирована на снижение негативного воздействия хозяйственной деятельности и эффективности выполнения экологических функций.

Эти условия выполнимы при разработке экологического каркаса городской территории (ЭКГТ). ЭКГТ включает важнейшие, ранжированные по режимам использования, согласно экологофункциональному зонированию, природно-антропогенные и антропогенные комплексы, обеспечивающие экологическую устойчивость развития города и сохранения комфортной среды обитания человека. В его основе - зеленые зоны; открытые водные пространства; искусственно созданные биогеоценозы, приспособленные для существования в условиях города; а также реставрационные земли. Последние представляют собой рекультивируемые площади на месте золоотвалов, оврагов, несанкционированных свалок, пустырейи т.д. Данные структурные элементы каркаса могут гармонично «вписаться» в общую планировочную структуру города, исходя из потенциально возможной роли в рамках эколого-функционального зонирования, которое предусматривает за каждым элементом закрепление и выполнение важнейших экологических функций. Значительные свободные межгородские пространства позволяют экологический каркас городской территории (локальный уровень), «связать» с элементами экологического каркаса более высокого (регионального) уровня.

А.В. Елизаров [3], разработавший концепцию ЭКТ Самарской области отмечает, что в долговременном плане ЭКТ не ведет к деградации территории, не снижает, а многократно увеличивает экономическую выгоду использования земель, обеспечивая длительное неистощительное сосуществование человека и используемых им природных ресурсов, что является фундаментальной задачей политики и управления. 3.Г. Мирзеханова [6], определяя приоритетные направления региональной экологической политики, отмечает, что экологический каркас территории является механизмом реализации одного из них - экологостратегического.

Формирование ЭКГТ должно быть органически увязано с планированием городской территории, с общими закономерностями развития урбанизации. Он должен стать составной частью совершенствования структуры городов.

Выводы. Существующее традиционное зонирование городской территории, представленное в Правилах землепользования и застройки, не предполагает выявление средоформирующих и средостабилизирующих свойств земель. Для целей устойчивого развития все земли, обладающие экологическими функциями, необходимо выделить в особую группу, придать им статус - земли экологического назначения и учитывать их в градостроительных документах. Эти условия выполнимы при разработке экологического каркаса городской территории (ЭКГТ), который является моделью, направленной на снижение негативного воздействия хозяйственной деятельности и эффективность выполнения экологических функций.

\section{БИБЛИОГРАФИЧЕСКИЙ СПИСОК REFERENCES}

1. Воронов Б.А., Мирзеханова 3.Г., Нарбут Н.А.. Особенности концепции Программы по улучшению экологического состояния города Хабаровска на 2011-2015 гг. // Вестник ДВО РАН. 2011. - № 2. - С. 83-87.

VoronovB.A. MirzekhanovaZ.G., NarbutN.A. Osobennosti kontseptsii programmy po uluchsheniyu ekologicheskogo sostoyaniya goroda Habarovska na 2011-2015 gg. [Specifics of the concept of the Program on Improvement of Khabarovsk City Ecological State for 2011-2015]. Bulletin FEBRAS. - 2011. - № 2. - pp. 83-87. (in Russian).

2. Долгосрочная целевая программа «Улучшение экологического состояния города Хабаровска на 2011-2015 гг.». Хабаровск: МБУ «Хабаровские вести». - 2011. -81С.

Dolgosrochnaya tselevaya programma 'Uluchshenie ekologicheskogo sostoyaniya goroda Habarovska $n$ a2011-2015gg.' [Long-term target program 'Improvement of Khabarovsk City Ecological State for 2011-2015']. Khabarovsk: MBU‘Khabarovsknews'. - 2011. - 81 p. (in Russian).

3. Елизаров A.B. О создании экологического каркаса Самарской области //Экологическая безопасность и устойчивое развитие Самарской области. Самара:Изд-во Гос. Комитета по охране окружающей среды Самарской области.. - 1998. - Вып. 6. -С. 76-91.

Elizarov A.V. O sozdanii ekologicheskogo karkasa Samarskoi Oblasti // Ecologicheskaya bezopasnost I ustoichivoe razvitie Samarskoi Oblasti [On the creation of an ecological carcass of Samarskaya Oblast // Ecological 
safety and sustainable development of Samarskaya Oblast]. Samara: Publ. House of the Samarskaya Oblast Committee on Environment Protection). - 1998. -Vol. 6. - pp. 76-91 (in Russian).

4. Морозова Г.Ю. Электронная база данных «Городские зеленые насаждения» для устойчивого развития городской территории // ИнтерКарто-ИнтерГИС-18: Устойчивое развитие территорий: теория ГИС и практический опыт. Матер. междунар. конф.Смоленск, 26-28 июня, - 2012 г. Смоленск, - 2012. -C. 351-354.

Morozova G.Yu. Elektronnaya baza dannyh "Gorodskie zelenye nasazhdeniya dlya ustoichivogo razvitiya gorodskoi territorii // InterCarto-InterGIS-18: Ustoichivoe razvitie territorii: teoriya GIS I prakticheskii opyt [The electronic database 'Urban green spaces' for the sustainable development of urban area // InterCarto-InterGIS-18: Sustainable Development of Territories: GIS theory and practical experience]. Proc. Int. Conf. Smolensk, June 26-28, - 2012 Smolensk, - 2012. - pp. 351-354 (in Russian).

5. Мирзеханова 3.Г. Особенности региональной экологической политики в стратегии перспективного развития Хабаровского края // Тихоокеан. геология. - 2010. -Т. 29, - № 3. - С.119-125.

Mirzekhanova Z.G. Osobennosti regionalnoi ekologicheskoi politiki v strategii perspektivnogo razvitiya Habarovskogo Kraya [Specifics of the regional environmental policy in long-term development strategy of Khabarovsk Krai]. Pacificgeology. - 2010. - Vol. 29, - № 3. - pp. 119-125 (in Russian).

6. Мирзеханова 3.Г. Региональная экологическая политика: содержание и индикаторы реализации отдельных направлений //Вестник ДВО РАН. - 2014. - № 3. -С.77-84.

Mirzekhanova Z.G. Regionalnaya ekologicheskaya politika: soderzhanie i indikatory realizatsii otdelnyh napravlenii [The regional environmental policy: the content and indicators of implementation of some aspects] Bulletin FEB RAS. - 2014. -№ 3. -pp. 77-84 (in Russian).

7. Михайлов Ю.П. К вопросу о территориальной организации общества и организации территории //География и природные ресурсы. - 1998. - № 4. - С. 10-17.

MikhailovYu.P. K voprosu o territorialnoi organizatsii obschestva I organizatsii territorii [On the question ofterritorial organization of society and the organization of the territory].Geography and natural resources. - 1998. - № 4. - pp.10-17 (in Russian).

8. Нарбут Н.А., Мирзеханова 3.Г. Особенности экологического планирования городской территории в регионах нового освоения (на примере Хабаровска) // ИнтерКарто-ИнтерГИС-20: Устойчивое развитие территорий: картографо-геоинформационное обеспечение. Матер. Междунар. конф. Белгород, Харьков (Украина), Кигали (Руанда) и Найроби (Кения), 23 июля-8 августа 2014г. - С. 530-535.

NarbutN.A.MirzekhanovaZ.G. Osobennosti ekologicheskogo planirovaniya gorodskoi territorii v regionah novogo osvoeniya (na primere Habarovska) // InterCarto-InterGIS-20: ustoichivoe razvitie territorii: kartografogeoinformatsionnoe obespechenie [Specifics ofecological planningin urban areain regions of new development(Khabarovsk as an example)// InterCarto/InterGIS-20: Sustainable Development of Territories: cartography andGISsoftware].Proc.Int.Conf. Belgorod, Kharkov (Ukraine), Kigali (Rwanda) and Nairobi (Kenya), 23 July-8 August 2014. - pp. 530-535 (in Russian).

9. Пивоваров Ю.А. Основы геоурбанистики: Урбанизация и городские системы: Учеб. пособие для студ. высш. учеб. заведений. М.:Гуманит. изд. ЦентрВЛАДОС, -1999. - 232 С.

Pivovarov Yu.A. Osnovy geourbanistiki: Urbanizatsiya I gorodskie sistemy [Basics of geourbanistics: Urbanization andurban systems]. Guidebook for academic students.Moscow: Human.Ed. Center VLADOS, - 1999. -232 p. (in Russian).

10. Правовое зонирование: Опыт разработки «Правил землепользования и застройки в городах России» /Под редакцией А. Высоковского и У. Валлеты. М.: Русская панорама. - 1999. - 20 С.

Pravovoe zonirovanie: Opyt razrabotki 'Pravil zemlepolzovaniya I zastroiki v gorodah Rossii' [Legal zoning: Experience in developmentof 'Rules ofland use and developmentin the citiesof Russia'].Ed. A.Vysokovsky and Yu.Valletta. Moscow:Russkaya panorama. - 1999. - 20 p. (in Russian).

11. Экология города (коллектив авторов) // Под редакцией А.С. Курбатовой, В.Н. Башкина, Н.С. Касимова. М: Научныймир. - 2004. - 624 С.

Ekologiaya goroda [Ecology of a city (group of authors)]. Ed. ASKurbatova, VNBashkin, NSKasimov. Moscow:Nauchnyimir. - 2004. - 624p. (in Russian). 